\title{
What patient data should be collected in this randomized controlled trial in sepsis?
}

\author{
Jean-Louis Vincent ${ }^{1 *} \mathbb{D}$, Ignacio Martin-Loeches ${ }^{2,3}$ and Djillali Annane ${ }^{4}$
}

(C) 2016 Springer-Verlag Berlin Heidelberg and ESICM

Prior to starting a study, senior investigators are often asked what kind of variables should be collected. Most will stress the simplicity of the question, grasp a pen and a piece of paper, and start to write a list so familiar that they know it by heart. But, research is somewhat subjective and, in addition to the fact that they may simply forget an item on their list, they may also overlook some element(s) they believe is (are) unimportant but which may be considered essential by others. Moreover, the collection of some data, perhaps not directly relevant to the intervention in question, may be useful for secondary analyses. Hence, this process needs to be more systematic. Having a standard reference list available as a model would also free up some of the senior researchers' precious time!

In a recent article in Intensive Care Medicine, Pettilä et al. [1] report their findings regarding the incomplete description of septic patients enrolled in randomized controlled trials (RCTs). More specifically, they documented that recent trials in septic shock have provided insufficient data on the treatments and hemodynamic values of the control groups. In the 24 studies analyzed, only about half of the data considered necessary for evaluation of the control group was actually reported in the main paper. In particular, only one-fifth of RCTs provided the data on baseline vasopressor use and lactate levels necessary to make a diagnosis of septic shock. This report highlights a serious problem, which may, at least in part, be prevented by the availability of an appropriate checklist.

To take the checklist idea one step further, we have devised a list (Table 1) that could be considered as a

\footnotetext{
*Correspondence: jlvincent@intensive.org

${ }^{1}$ Department of Intensive Care, Erasme University Hospital, Unversité

Libre de Bruxelles, Brussels, Belgium

Full author information is available at the end of the article
}

template for data collection in sepsis trials, including both baseline data and data that should be collected during the study.

The table presents a standard minimum set of baseline data, grouped according to the PIRO (predisposition, infection, response, organ failure) construct [2]; obviously, it will need to be adapted to the type of study. For example, a study on antibiotics will require more details about microorganisms than a study on mechanical ventilation, which may in turn require blood gas data. Additional information on the degree of malnutrition may be needed for a study on nutritional support. Specific biomarkers should be measured for specific interventions. As an example, coagulation markers should be collected in a study on a drug targeting coagulopathy, and gamma-globulin levels in a study on gamma-globulin administration.

Data collection is not without difficulty, with notable hurdles already present in the recording of baseline variables. This is true whether or not data are automatically collected from the electronic medical record. What should we do when there are two temperature measurements or several central venous pressure measurements recorded during the initial period of evaluation? The question is even more complex for variables that are monitored continuously. Which value should be recorded for the baseline heart rate, arterial pressure, or cardiac output (when it is measured continuously)? There may be substantial fluctuation over time, and little attention has been paid to the best way of reporting these values. Should we average them over a period of time? Or does this actually matter very much?

Data collection during the subsequent days must also be adapted to the type of study. For example, a study on shock should include repeated lactate levels [3]. Other relevant biomarkers (general or specific for the

\section{Springer}




\section{Table 1 Proposed minimum data collection for a clinical trial in septic patients}

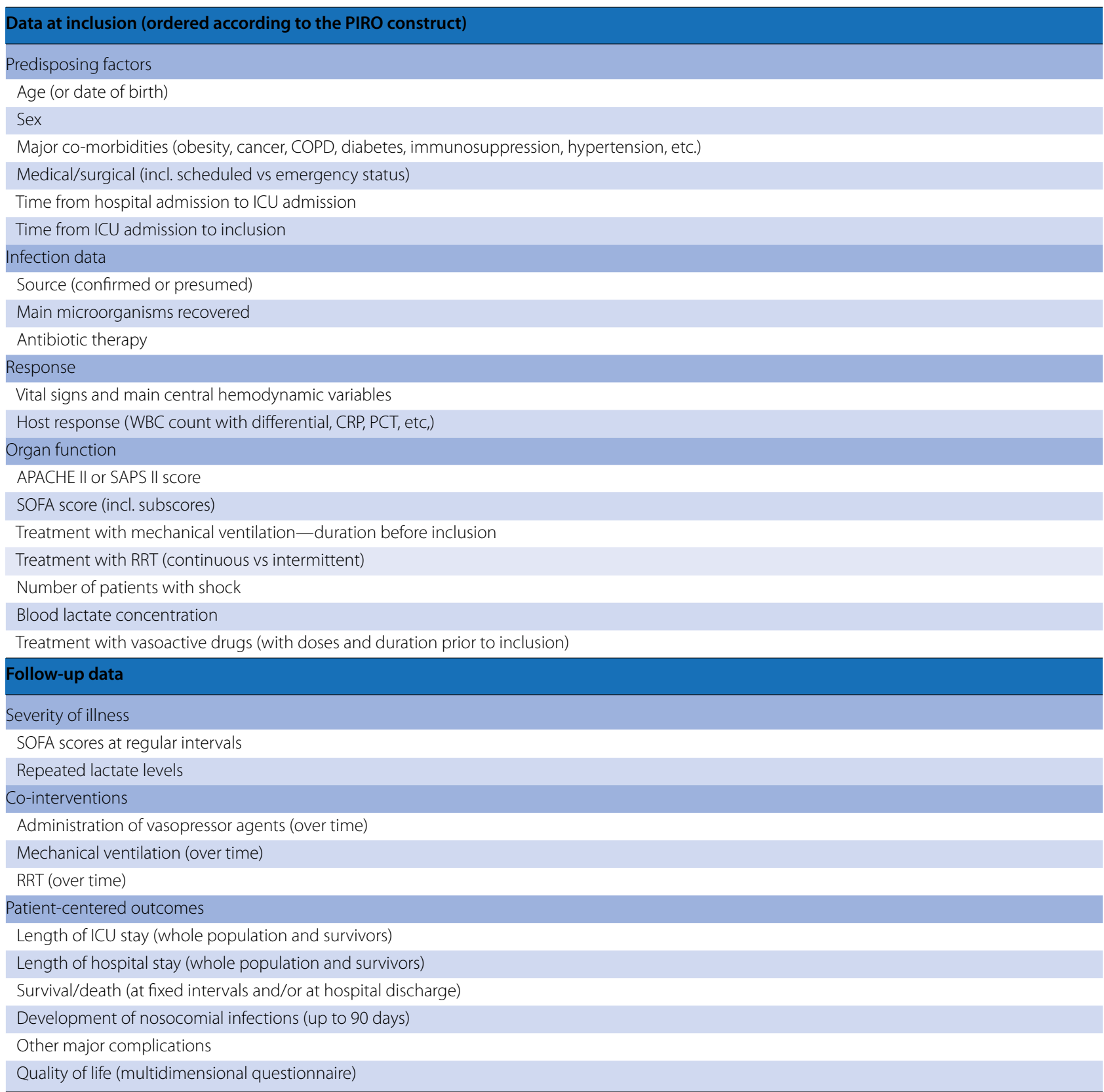

COPD chronic obstructive pulmonary disease, WBC white blood cell, CRP C-reactive protein, $P C T$ procalcitonin, SOFA sequential organ failure assessment, $R R T$ renal replacement therapy

intervention) should be collected at regular intervals. Measurement of procalcitonin (PCT) levels over time may be relevant in some studies to evaluate the evolution of the host response over time. The precise time interval that should be used between measurements is difficult to define and will vary according to the particular variable, patient status, and the aims and targets of the study. While for most variables, a daily measurement is likely sufficient, for others more or less frequent measures may be appropriate.

Collection of these data during the study period can also be a challenge. For example, if we want to record the fluid balance-and we should do so more often than is currently the case-which time period should we use? To be completely accurate, 24-h fluid balance should be measured for each 24-h period starting from the time of 
patient admission. But patients can be admitted at any time of the day or night, making this approach difficult from a practical point of view. Fluid balances would need to be collected and calculated at different hours of the day and night for different patients, while in general these measurements are made routinely by the nurses once a day at the same time for all patients, often early in the morning. Patient data management systems do not help much in this regard. Another option is to calculate the fluid balance for the period from admission to the usual time at which fluid balance is estimated and extrapolate it to a 24-h period, but this can create bias. For example, a patient who is admitted at 0200 hours and is transiently oliguric may have a very positive fluid balance for the first few hours (until the standard early morning calculation of daily fluid balance), but not over the first $24 \mathrm{~h}$. Extrapolation of the urine output from the first few hours to the entire 24-h period would result in a false recording of prolonged oliguria and a falsely high fluid balance.

Another issue is evaluation of vasoactive drug use. Too often, studies simply record whether or not drugs, such as adrenergic agents or other inotropic agents, were administered. This is particularly true for norepinephrine, doses of which can vary substantially over time. A dichotomized "yes" or "no" answer does not provide any information on the dosing level, e.g., whether it remained below $0.5 \mu \mathrm{g} / \mathrm{kg} / \mathrm{min}$, oscillated between 2 and $10 \mu \mathrm{g} / \mathrm{kg} /$ min, or swung between 0.2 and $5 \mu \mathrm{g} / \mathrm{kg} / \mathrm{min}$. Moreover, the addition of other vasopressors, including phenylephrine or vasopressin derivatives, further complicates the measurements. Some authors have proposed calculation of scoring systems, such as the adrenergic score [4], the vasoactive-inotropic score [5], and the vasopressor dependency index [6], but these are far from ideal.

Clearly there is no definitive answer to these important questions, but improved reporting is certainly needed and we hope the proposed table will help investigators as they prepare their next study in the field of sepsis.

\section{Author details}

${ }^{1}$ Department of Intensive Care, Erasme University Hospital, Unversité Libre de Bruxelles, Brussels, Belgium. ${ }^{2}$ Multidisciplinary Intensive Care, Department of Clinical Medicine, Trinity College, Welcome Trust-HRB Clinical Research Facility, St James's University Hospital, Dublin, Ireland. ${ }^{3}$ CIBER de Enfermedades Respiratorias (CIBERes), Madrid, Spain. ${ }^{4}$ General Intensive Care Unit, Raymond Poincaré Hospital (APHP), Laboratory of Infection and Inflammation, U1173 INSERM and University of Versailles, 92380 Garches, France.

\section{Compliance with ethical standards}

\section{Conflicts of interest}

The authors have no conflicts of interest to declare related to this manuscript.

Received: 15 July 2016 Accepted: 15 September 2016

Published online: 4 October 2016

\section{References}

1. Pettilä V, Hjortrup PB, Jakob SM, Wilkman E, Perner A, Takala J (2016) Control groups in recent septic shock trials: a systematic review. Intensive Care Med. doi:10.1007/s00134-016-4444-y

2. Levy MM, Fink MP, Marshall JC, Abraham E, Angus D, Cook D, Cohen J, Opal SM, Vincent JL et al (2003) 2001 SCCM/ESICM/ACCP/ATS/SIS international sepsis definitions conference. Crit Care Med 31:1250-1256

3. Vincent JL, Quintairos e Silva A, Couto L Jr, Taccone FS (2016) The value of blood lactate kinetics in critically ill patients: a systematic review. Crit Care 20:257

4. Wernovsky G, Wypij D, Jonas RA, Mayer JE Jr, Hanley FL, Hickey PR, Walsh AZ, Chang AC, Castaneda AR et al (1995) Postoperative course and hemodynamic profile after the arterial switch operation in neonates and infants. A comparison of low-flow cardiopulmonary bypass and circulatory arrest. Circulation 92:2226-2235

5. Gaies MG, Gurney JG, Yen AH, Napoli ML, Gajarski RJ, Ohye RG, Charpie JR, Hirsch JC (2010) Vasoactive-inotropic score as a predictor of morbidity and mortality in infants after cardiopulmonary bypass. Pediatr Crit Care Med 11:234-238

6. Cruz DN, Antonelli M, Fumagalli R, Foltran F, Brienza N, Donati A, Malcangi V, Petrini F, Volta G et al (2009) Early use of polymyxin B hemoperfusion in abdominal septic shock: the EUPHAS randomized controlled trial. JAMA 301:2445-2452 